\title{
ADVANTAGES OF COLOUR ETCHING IN QUALITY CONTROL OF RECYCLED AI-Si CAST ALLOYS
}

doi: 10.2478/cqpi-2019-0040

Date of submission of the article to the Editor: 29/03/2019

Date of acceptance of the article by the Editor: 24/05/2019

Eva Tillová ${ }^{-}$- orcid id: 0000-0002-1010-0713

Lenka Kuchariková ${ }^{1}$ - orcid id: 0000-0002-2688-1075

Mária Chalupová ${ }^{1}$ - orcid id: 0000-0003-0175-9484

Juraj Belan ${ }^{1}$ - orcid id: 0000-0002-2428-244X

Alan Vaško ${ }^{1}$ - orcid id: 0000-0002-3937-2691

Adrián Herčko ${ }^{1}$ - orcid id: 0000-0003-0412-9533

1 University of Žilina, Faculty of Mechanical Engineering, Depatment of Materials Engineering, Univerzitná 8215/1, 010 26, Slovakia

Abstract: Colour Metallography is a set of light metallographic microscopy methodologies that utilize phase colour contrast as a source of new structure information compared to conventional techniques. In many cases, colour contrast can be induced where no identifiable phase contrast is obtained by conventional techniques. With the help of colour contrast, we gain new information on the structure of Al-Si alloys, especially intermetallic phases, in which the benefits of its use in casting quality control are of benefit.

Blue-yellow contrast is definitely more pronounced than dark grey or light grey contrast. There is no substantial reproducible colour reproduction, since it is irrelevant whether the two phases are distinguished by blue-yellow or green-ocher contrast. When using the colour contrast, the structural components differ not only according to their microscopic appearance, but also based on the knowledge of the chemical composition of alloys, interactions between structural components, knowledge of the possible influence of Al-alloys structure (e.g. refining, modifications, heat treatment). Colour contrast in quality control of $\mathrm{Al}-\mathrm{Si}$ alloys was applied to AISiMg cast alloy (AISi7Mg0.3; AlSi7MgTi; AlSi10MgMn; etc.)

Keywords: Al-Si cast alloys, colour metallography, microstructure, and quality control

\section{INTRODUCTION}

Castings from aluminium alloys are widely used in production of machines and devices made in the technological processes. Aluminium alloys are especially preferred in designs thanks to their good mechanical properties and possibility to make very complicated castings with high service properties. Thanks to the contemporary casting and heat treatment technologies, castings from the aluminium alloys have the suitably high mechanical properties and simultaneously decrease the part weight. Therefore, there are more and more frequently used in the means of transport industry (Tillová and Chalupová, 2009). 
Recycling is a major consideration in continued aluminium use, representing one of the key attributes of this ubiquitous metal, with far-reaching economic, ecological and social implications. More than half of all the aluminium currently produced in the European Union originates from recycled raw materials and that trend is on the increase. In view of growing end-use demand and a lack of sufficient domestic primary aluminium production in this part of the world, Europe has a huge stake in maximising the collection of all available aluminium, and developing the most resource-efficient scrap treatments and melting processes. The importance of efficient aluminium recycling will even further increase in the future because of rising energy constraints in this region. For most aluminium products, aluminium is not actually consumed during a lifetime, but simply used. Therefore, the life cycle of an aluminium product is not the traditional "cradle-to-grave" sequence, but rather a renewable "cradle-to-cradle". If scrap is processed appropriately, the recycled aluminium can be utilised for almost all aluminium applications, thereby preserving raw materials and making considerable energy savings (Das and Gren, 2010; VDS, 2000; Schlesinger, 2007).

Recycled aluminium is aluminium ingot obtained by recycling of scrap. Typical products made from recycled aluminium include castings like cylinder heads, engine blocks, gearboxes and many other automotive and engineering components on the one hand, and extrusion billets or rolling ingots for the production of profiles, sheets, strips and foil on the other (VDS, 2000; Kuchariková et al., 2016a).

An increasing amount of recycled aluminium is going into the production of aluminium alloy used for automotive applications (Fig. 1, Wang, 2014). In these applications, it is necessary to control casting quality.

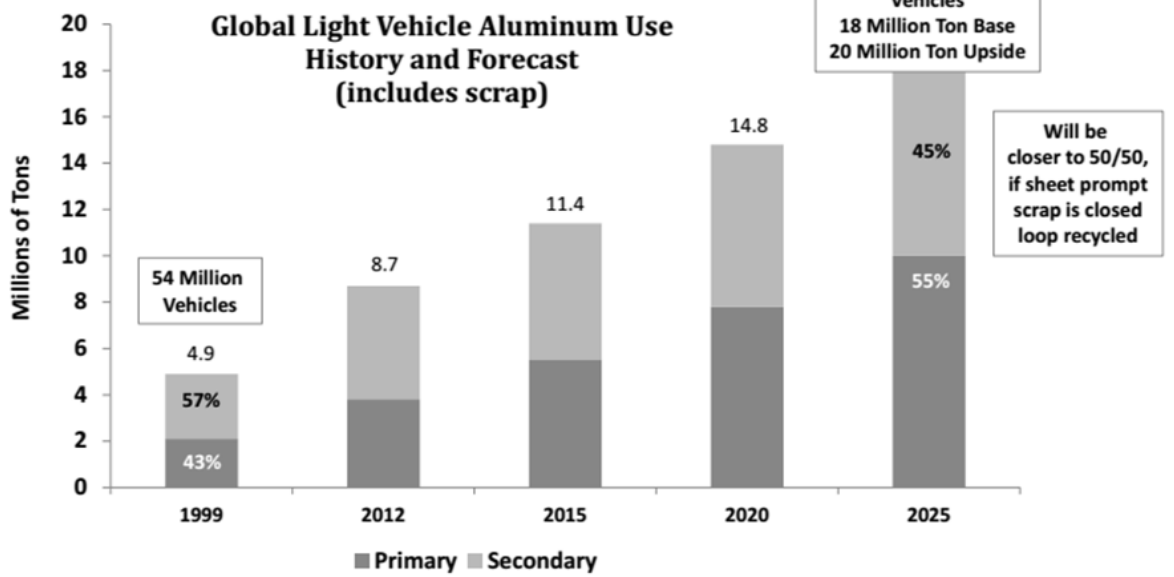

Fig. 1. Global light vehicle aluminium use (Ducker Worldwide)

The quality of recycled Al-Si casting alloys is considered to be a key factor in selecting an alloy casting for a particular engineering application. By implementing adaptable alloying- and process technology, the mechanical properties will therefore be radically enhanced, leading to larger application fields of complex cast aluminium components such as safety details. Generally, the mechanical and microstructural properties of aluminium cast alloys are dependent on the composition (Badgayan, 2013; Fabrizi et 
al., 2013; Farkašová et al., 2013; Li et al., 2017; Shaha et al., 2016); melt treatment conditions, solidification rate (Fabrizi et al., 2015), casting process and the applied thermal treatment (Barhoumi et al., 2015; Manente and Timelli, 2011).

$\mathrm{Al}-\mathrm{Si}$ alloys usually contain $\mathrm{Si}$ and sometimes $\mathrm{Mg}$ or $\mathrm{Cu}$ as the main alloying elements ( $\mathrm{Mg}$ and $\mathrm{Cu}$ strengthen the alloy matrix and improve the mechanical properties and alloy machinability), together with various impurities such as Fe, Mn, Zn or Cr. During the industrial processing of the Al-Si alloys, these elements go into solid solution but they also form different intermetallic phases (Fabrizi et al., 2015; Shabsestari, 2004; Samuel et al., 2014; Tillová and Chalupová, 2009; Tillová et al., 2011a).

The demand for high performance cast aluminium alloy components are often disturbed by increasing impurity elements, such as iron accumulated from recycled scraps. The solid solubility of iron in molten aluminium is about $0.03-0.05 \mathrm{wt}$. \% at the eutectic temperature of $655^{\circ} \mathrm{C}$. Thus, most of the iron present above this level appears in the form of iron intermetallic phases. When iron combines with $\mathrm{Al}$ and $\mathrm{Si}$, it forms a $\beta-\mathrm{Al}_{5} \mathrm{FeSi}$ intermetallic phase displaying a platelet-like shape (needles in the microstructure). The $\mathrm{Al}_{5} \mathrm{FeSi}$ phase is considered the most critical among the iron intermetallics, as it significantly reduces the alloy ductility, fracture toughness and fatigue and corrosion properties (Sága et al., 2012; Závodská et al., 2017). In comparison, the $\alpha$-iron phase $\mathrm{Al}_{15}\left(\mathrm{FeMn}_{3} \mathrm{Si}_{2}\right.$, due to its compact morphology (skeleton-like or chines script), is less harmful to the mechanical properties (Hurtalová et al., 2014a; Samuel et al., 2018; Shabsestari, 2004; Taylor, 2004; Taylor, 2012).

Because of the commercial and technological importance of recycled cast aluminium alloys increases; these processes have been the subject of extensive research for several decades aiming at improving the quality of recycled cast alloys. The present study is a part of larger research project, which was conducted to investigate and to provide better understanding properties of recycled Al-Si cast alloys. The main objective of this work was to study the possibility use of colour contrast in the analysis of intermetallic phases in recycled aluminium cast alloys.

\section{METHODOLOGY OF RESEARCH}

Metallography of aluminium is used in quality control for grain size determination and for microstructure defects on the polished and etched specimen. Cast alloys are evaluated for shape and distribution of phases (morphology of eutectic Si, morphology of intermetallic phases) and possible porosity (Hurtalová et al., 2014b; Kuchariková et al., 2016b; Tillová et al., 2011a). In wrought material, defects from the rolling and extrusion process are investigated and plating thicknesses measured.

The observed contrast of metallographic specimens can be enhanced by nondestructive techniques or by altering the surface with etchants. Optical methods allow nondestructive enhancement of contrast by various illumination modes common to metallurgical reflected light microscopes. These optical techniques include darkfield illumination, polarized light microscopy, phase contrast microscopy, and differential interference contrast. Microstructural contrast can be enhanced by the formation of a thin transparent film on the specimen surface. Incident light is partially absorbed by the film and is repeatedly reflected at the layer/specimen interface before exiting. Thickness of the film is controlled to produce interference effects and colour contrast. A very thin layer absorbs all the wavelengths and gives a grey contrast. Thickening of the layer causes interference effects, which result in cancellation of 
particular wavelengths and the intensification of colour contrast (ASM Handbook, 2004; Tillová and Chalupová, 2014).

As an experimental material were used scrap-based - recycled alloys (AISi9Cu3, AlSi7Mg0.3 and AISi10MgMn. The samples for metallographic observations $(1.5 \mathrm{~cm} \mathrm{x}$ $1.5 \mathrm{~cm}$ ) were sectioned from the test bars and prepared. A conventional grinding and polishing process consisting of wet grinding on increasingly finer 500 and 1200 grade round SiC grinding papers (Struers TegraPol-15). The samples were then polished with $3 \mu \mathrm{m}$ diamond pastes followed by Struers Op-S. Subsequently, etching sample preparation for observation in optical microscope (Neophot 32) was carried out in these steps:

- standardly etched by standard reagent $0.5 \% \mathrm{HF}$, Dix-Keller or $\mathrm{H}_{2} \mathrm{SO}_{4}$ (Table 1).

- colour etched by Weck-Al or MA (Table 1).

After etching the specimens were washed under running water, then ethanol, and dried.

Table 1

Reagent for standard and colour etching

\begin{tabular}{|c|c|c|c|}
\hline & $\begin{array}{l}\text { Chemical } \\
\text { composition }\end{array}$ & Preparation & Etching \\
\hline $0.5 \% \mathrm{HF}$ & $\begin{array}{l}100 \mathrm{ml} \mathrm{H} \mathrm{O}_{2} \\
0.5 \mathrm{ml} \mathrm{HF}\end{array}$ & In to distillers waters ad HF. & $\begin{array}{l}\text { At ambient temp., } 20-50 \mathrm{~s} \text { to } \\
\text { alternately polish and etch } \\
\text { several times. }\end{array}$ \\
\hline Dix-Keller & $\begin{array}{l}10 \mathrm{ml} \mathrm{HF} \\
15 \mathrm{ml} \mathrm{HCl} \\
25 \mathrm{ml} \mathrm{HNO}_{3} \\
950 \mathrm{ml} \mathrm{H}_{2} \mathrm{O} \\
\end{array}$ & $\begin{array}{l}\text { In to distillers waters ad } \mathrm{HF}+ \\
\mathrm{HCl}+\mathrm{HNO}_{3} \text {. }\end{array}$ & At ambient temp., cca $1 \mathrm{~s}$. \\
\hline $\mathrm{H}_{2} \mathrm{SO}_{4}$ & $\begin{array}{l}20 \mathrm{ml} \mathrm{H}_{2} \mathrm{SO}_{4} \\
100 \mathrm{ml} \mathrm{H}_{2} \mathrm{O}\end{array}$ & $\begin{array}{l}\text { In to distillers waters ad } \\
\mathrm{H}_{2} \mathrm{SO}_{4} \text {. }\end{array}$ & At $70^{\circ} \mathrm{C}\left(160^{\circ} \mathrm{F}\right), 30 \mathrm{~s}-1 \mathrm{~min}$ \\
\hline Weck-Al & $\begin{array}{l}\mathrm{g} \mathrm{KMnO} 4 \\
1 \mathrm{~g} \mathrm{NaOH} \\
100 \mathrm{ml} \mathrm{H}_{2} \mathrm{O} \\
\end{array}$ & $\begin{array}{l}\text { In to gently warm distillers } \\
\text { waters ad } \mathrm{KMnO}_{4}+\mathrm{NaOH} \text {. }\end{array}$ & $\begin{array}{l}\text { At ambient temp., } 5 \text { - } 45 \mathrm{~s} \text { until } \\
\text { the surface is coloured (brown); } \\
\text { prepare fresh before use. }\end{array}$ \\
\hline MA & $\begin{array}{l}100 \mathrm{ml} \mathrm{HNO}_{3} \\
100 \mathrm{ml} \text { ethyl } \\
\text { alcohol } \\
2-2.5 \mathrm{~g} \\
\left(\mathrm{NH}_{4}\right)_{6} \mathrm{Mo}_{7} \mathrm{O}_{24}\end{array}$ & $\begin{array}{l}\text { In to ethyl alcohol ad } \mathrm{HNO}_{3}+ \\
\left(\mathrm{NH}_{4}\right)_{6} \mathrm{Mo}_{7} \mathrm{O}_{24} \text {. }\end{array}$ & At ambient temp., 20 - $50 \mathrm{~s}$. \\
\hline
\end{tabular}

Source: (Tillová and Chalupová, 2009; ASM Handbook, 2004).

\section{RESULTS}

Typical microstructures of the as-cast cast alloys are shown in Fig. 2 and Fig. 3. The microstructure of recycled Al-Si cast alloy after standard etching (black and white) consists of dendrites $\alpha$-phase (light grey), eutectic (mixture of $\alpha$-matrix and spherical grey Si-phases) and variously type's intermetallic phases. The a-matrix precipitates from the liquid as the primary phase in the form of dendrites and is nominally comprised of $\mathrm{Al}$ and $\mathrm{Si}$. Intermetallic particles had different morphologies, such as platelet or needles $\left(\mathrm{Al}_{5} \mathrm{FeSi}\right)$, skeleton/script-like/Chinese script $\left(\mathrm{Al}_{15}(\mathrm{FeMn}-\mathrm{Mg})_{3} \mathrm{Si}_{2}\right.$ or AlFeMn), oval $\left(\mathrm{Al}_{2} \mathrm{Cu}\right)$ and fine spheroidal particles $\left(\mathrm{Mg}_{2} \mathrm{Si}\right)$ too.

As recycling of aluminium alloys becomes more common, Fe-rich phases or hard sludge phases will be a problem of increasing importance due to the concentration of 
$\mathrm{Fe}, \mathrm{Mn}, \mathrm{Cr}$ and $\mathrm{Si}$ in the scrap cycle. Mechanical properties are principally controlled by the cast structure. Therefore, for a given composition (and heat treatment), it is the ability to optimize structural factors. Thus microstructural control of phases is of considerable technological importance.

In the standard black and white etching of aluminium alloys ( $0.5 \mathrm{HF}$ or Dix-Keller), it is not always possible to achieve sufficient contrast of all phases present in the observed structure (Fig. 2). The means of expression and the light microscopy information value in assessing in particular intermetallic phases can significantly enhance the use colour contrast of structural components that can be achieved by using available light microscope attachments or by surface treatment of metallographic samples.

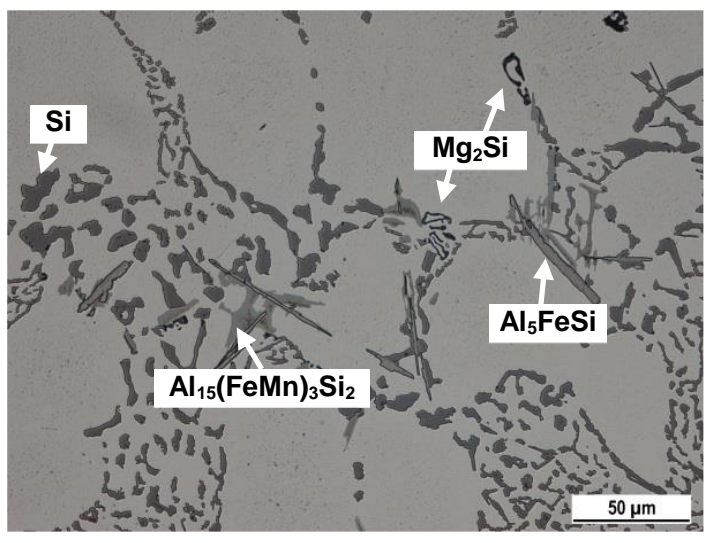

a) AISi7Mg0.3, etch. $0.5 \% \mathrm{HF}$

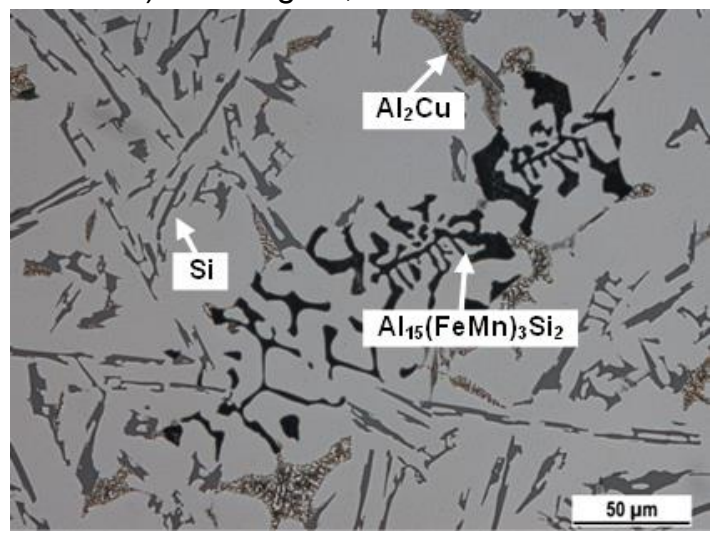

c) AISi9Cu3, etch. $\mathrm{H}_{2} \mathrm{SO}_{4}$

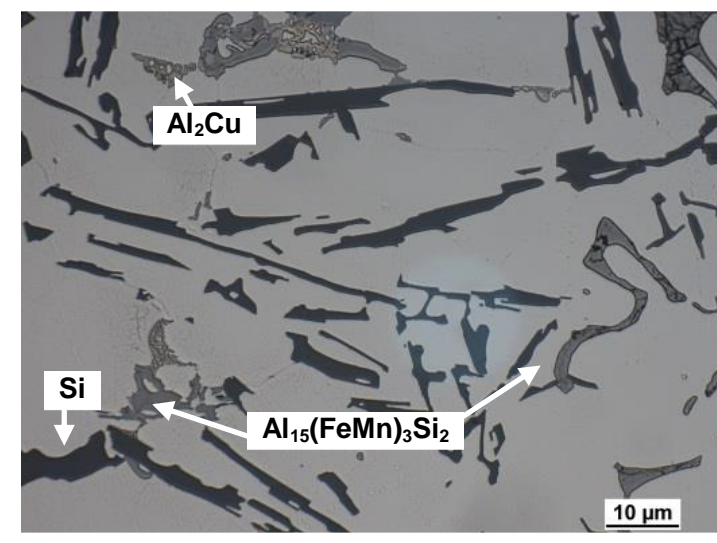

b) AISi9Cu3, etch. $0.5 \% \mathrm{HF}$

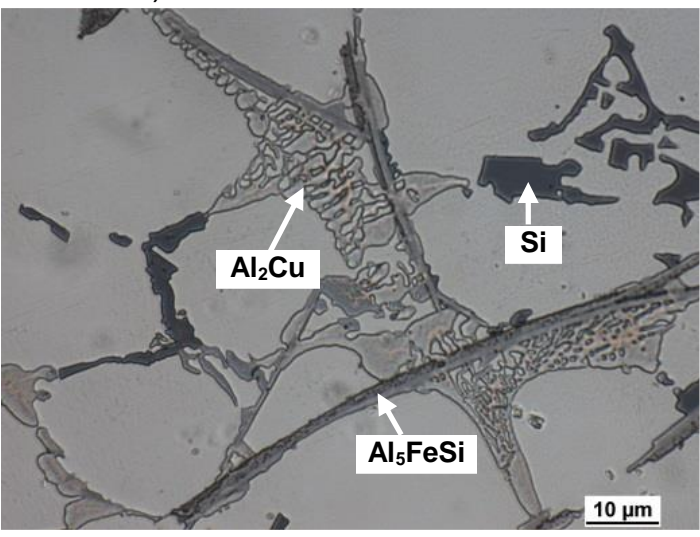

d) AISi9Cu3, etch. Dix-Keller

Fig. 2. Microstructure of Al-Si alloys etched by standard reagent

The colour contrast between the individual microlocalities is in rare cases due to the natural chromaticity of some phases. More often, it is artificially induced and arises due to the different properties of the particles in polarized light, or by the interference of phases-shifted waves due to their reflection from surface irregularities, due to different phase reflections, or due to multiple reflections in the transparent surface layer or the varying thickness of the transparent surface film (ASM Handbook, 2004). Colour contrast is successfully used to increase the contrast between phases, which are hardly visible after standard etching or are not sufficiently distinguishable from each other. After colour etching phases present in the microstructure have different colour from the eutectic silicon. This colouration is due to the different chemical composition of these phases, which, after chemical reaction with the etchant, form 
coatings with varying thickness. Therefore changes the colour of the individual microlocalities by observation in the light field. The chemical composition of the etchants is chosen so, that coatings with varying thicknesses of about 100 to $150 \mathrm{~nm}$ can be formed.

Microstructure of Al-Si cast alloys documented after the most commonly used etchants for colour etching is in Fig. 3. The $\mathrm{Al}_{5} \mathrm{FeSi}$ phase has a characteristic platelike/needle shape. After standard etching has a grey (Fig. 2a) or black (Fig. 2d) colour. After etching with MA are needles brown (Fig. 3a). Fe-rich phases $\mathrm{Al}_{15}(\mathrm{FeMn})_{3} \mathrm{Si}_{2}$ and $\mathrm{AlFeMn}$ are observed as skeleton-like/Chinese script formations, which are after standard etching light grey (Fig.2a, b). After etching by $\mathrm{H}_{2} \mathrm{SO}_{4}$ have skeleton like phases dark grey or black colour (Fig. 2c). This colour is very suitable for quantitative analyses. After colours etchings by MA have these phases light blue or light brown colour (Fig. 3a, b). By application Weck-Al etching the Fe-rich phases colours to light blue or light brown (Fig. 3c) too.

It is not possible to differentiate the $\mathrm{Al}_{15}(\mathrm{FeMn})_{3} \mathrm{Si}_{2}$ phase from the $\mathrm{Al}_{15}(\mathrm{FeMg})_{3} \mathrm{Si}_{2}$ phase by colour etching. The differentiation only allows for the observation of colouretched samples in polarized light (Fig. $3 \mathrm{~d}$ ), whereby the $\mathrm{Al}_{15}\left(\mathrm{FeMn}_{3} \mathrm{Si}_{2}\right.$ phase can be observed mainly as blue phase and the $\mathrm{Al}_{15}\left(\mathrm{FeMg}_{3} \mathrm{Si}_{2}\right.$ phase as violet phase.

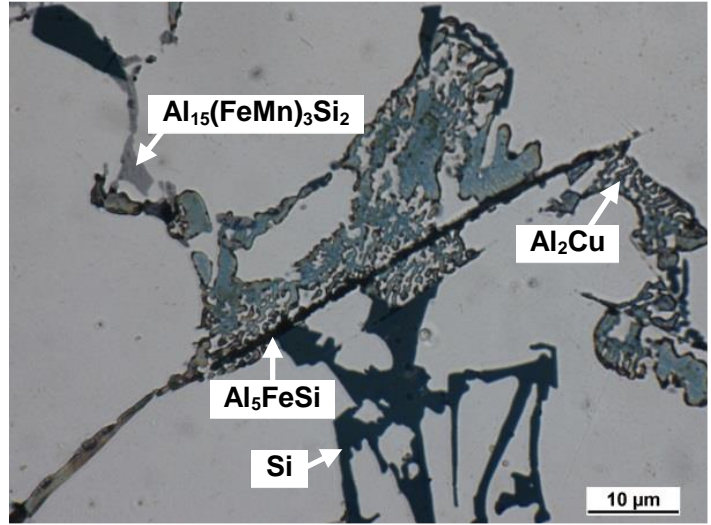

a) AISi9Cu3, etch. MA

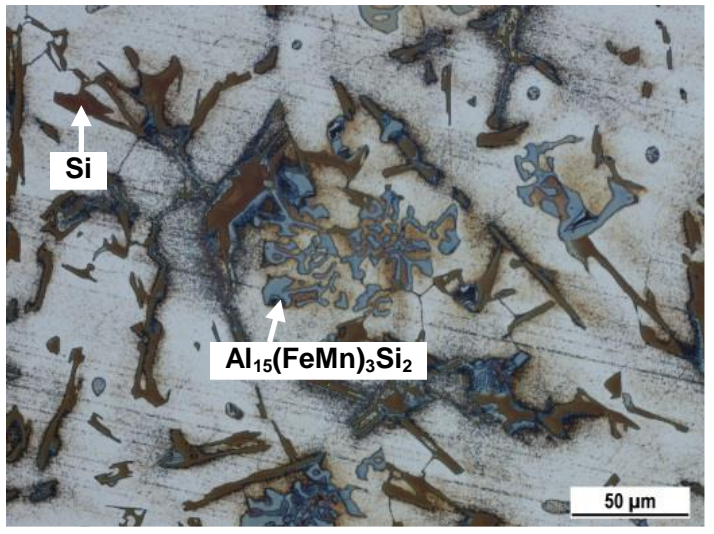

c) AISi9Cu3, etch. Weck-Al

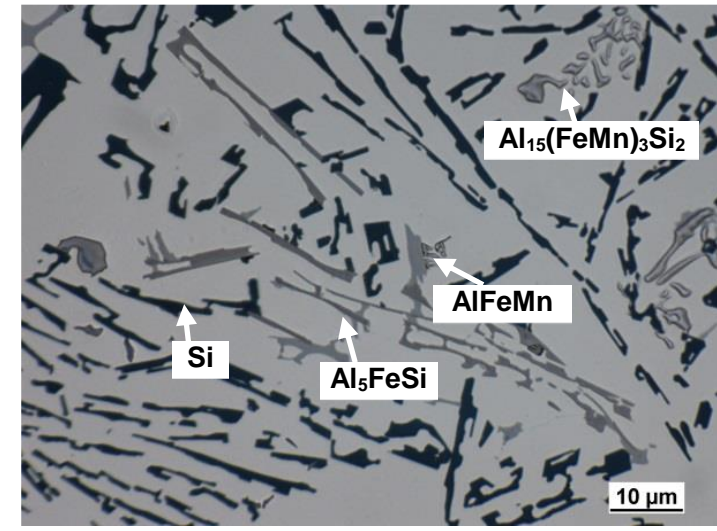

b) AISi10MgMn, etch. MA

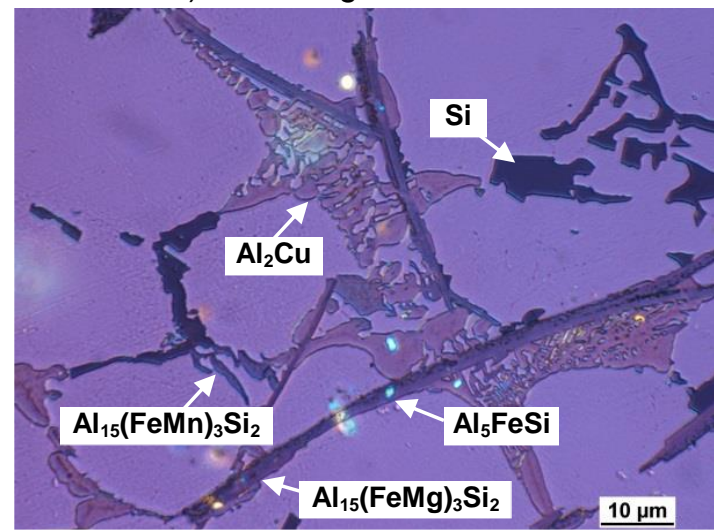

d) AISi9Cu3, etch. Dix-Keller, Pol. Light

Fig. 3. Microstructure of Al-Si alloys etched by "colour" reagent

The colour of the individual phases is irrelevant and is related to the etching time. The colours of phases documented in Fig. 3 are achieved with an optimally etched surface and recommended etching time. The reproduction colour may be different (depending 
up etching and chemical composition). But the final phase colour is not so crucial, but it is essential that the phases are identifiable.

\section{CONCLUSION}

The aim of this paper is to show how the colour metallography technique is proper to examine the structure of recycled cast aluminium alloys. In this case, utilizing the colour metallography we can obtain more information about structure of recycled Al-Si cast alloys to comparing the standard method and we can improve the quality of casting control. On the basis of the experimental results the following conclusions can be stated:

- The most common for practical use is a $0.5 \% \mathrm{HF}$ reagent. This reagent improves the image contrast, reveals little besides the intermetallics and has high reproducibility. $\mathrm{H}_{2} \mathrm{SO}_{4}$ is more suitable for quantitative analysis when we need to highlight only Fe-phases.

- Both colour etchants successfully supported optical visualisation, with good contrast between all phases. Weck-Al has the advantages of being chemically relatively innocuous and of not attacking intermetallic phases or precipitates, which are often etched away by many well-known etchants. One disadvantage of this etchant is its extremely sensitive reaction to remnant deformation layers on the surface of the prepared specimen.

\section{ACKNOWLEDGEMENTS}

This study has been supported by projects VEGA 01/0398/19 and KEGA 049ŽU4/2017. The authors would like to thank Mrs. Anna Macúchová for preparation of metallographic samples.

\section{REFERENCES}

ASM Handbook. 2004. Metalography and Microstructures. Volume 9. Materials Park, Ohio, USA.

Barhoumi. H. et al. 2015. Influence of heat treatment on the microstructures and mechanical properties of squeeze cast AlSigCu3 alloys. International Journal of Microstructure and Materials Properties. 10(5-6), 472-487. https://doi.org/10.1504/IJMMP.2015.074999

Badgayan, N. 2013. Investigation of effects of various alloying additions on properties of Al-Si casting alloy and analysis of iron as impurity in Al-Si casting alloy. International Journal of Engineering Research \& Technology. 2(9), 289-299.

Das, K. S., Gren, J. A. 2010. Aluminum Industry and Climate Change-Assessment and Responses. JOM - the journal of the Minerals, Metals and Materials Society, 62(2), 27-31.

Fabrizi, A., Ferraro, S., Timelli, G. 2013. The influence of Sr, Mg and Cu addition on the microstructural properties of a secondary AISigCu3(Fe) die casting alloy. Materials Characterization. 85, 13-25. https://doi.org/10.1016/j.matchar.2013.08.012

Fabrizi A. et all. 2015. Evolution of Fe-rich compounds in a secondary Al-Si-Cu alloy: Influence of cooling rate. International Journal of Materials Research. 106(7), 719724. https://doi.org/10.3139/146.111238

Farkašová, M., Tillová, E., Chalupová, M. 2013. Modification of Al-Si-Cu cast alloy. FME Transactions, New series, 41(3), 210-215.

Hurtalová, L., Tillová, E., Chalupová, M. 2014a. The Study of Iron Intermetallic Phases Morphology with Applying Deep Etching in Secondary Al-Si Alloys. Materials Science Forum. 782, 359-364. https://doi.org/10.4028/www.scientific.net/MSF.782.359 
Hurtalová, L., Tillová, E., Chalupová, M. 2014b. Optimalization of Eutectic Si Particles Morphology in Secondary Al-Si Cast Alloys after Different Heat Treatment. Advanced Materials Research. 1025-1026, 349-354.

https://doi.org/10.4028/www.scientific.net/AMR.1025-1026.349

Kuchariková, L., Tillová, E., Bokůvka, O., 2016a. Recycling and properties of recycled aluminium alloys used in the transportation industry. Transport problems. 11(2), 117-122. DOI: 10.20858/tp.2016.11.2.11

Kuchariková, L., Tillová, E., Chalupová, M., 2016b. The Si particles morphology in hypoeutectic Al-Si casts. Materials Today proceedings. 2(4), 1031-1036. https://doi.org/10.1016/j.matpr.2016.03.042

$\mathrm{Li}, \mathrm{Z}$. et al. 2017. Influence of $\mathrm{Sr}, \mathrm{Fe}$ and Mn content and casting process on the microstructures and mechanical properties of AlSi7Cu3 alloy. Materials Science and Engineering A. 689, 286-297. https://doi.org/10.1016/j.msea.2017.02.041

Manente, A., Timelli, G. 2011. Optimizing the heat treatment process of cast aluminium alloys. Recent Trends in Processing and Degradation of Aluminium Alloys, Zaki Ahmad, IntechOpen, DOI: 10.5772/21659

Sága, M., Kopas, P., Uhríčik, M. 2012. Modeling and Experimental Analysis of the Aluminium Alloy Fatigue Damage in the case of Bending - Torsion Loading. Procedia Engineering. 48, 599-606. https://doi.org/10.1016/j.proeng.2012.09.559

Samuel, E., Samuel, A.M., Doty, H.W., Valtierra, S. Samuel, F.H. 2014. Intermetallic phases in Al-Si based cast alloys: new perspective. International Journal of Cast Metals Research, 27(2), 107-114. https://doi.org/10.1179/1743133613Y.0000000083

Samuel, A.M., Samuel, F.H., Doty, H.W., Valtierra, S. 2018. Beta Al5FeSi phase platelets-porosity formation relationship in A319.2 type alloys. International Journal of Metalcasting 12(1), 55-70. https://doi.org/10.1007/s40962-017-0136-9

Shaha, S.K. et al. 2016. Effect of Cr, Ti, V, and Zr micro-additions on microstructure and mechanical properties of the Al-Si-Cu-Mg cast alloy. Metallurgical and Materials Transactions A: Physical Metallurgy and Materials Science. 47(5), 23962409. https://doi.org/10.1007/s11661-016-3365-2

Shabsestari, S.G. 2004. The effect of iron and manganese on the formation of intermetallic compounds in aluminum-silicon alloys. Mater. Sci. Eng. A, 383, 289298. https://doi.org/10.1016/j.msea.2004.06.022

Schlesinger, M. 2007. Aluminum recycling. Boca Raton, FL. CRC Press, Taylor \& Francis Group.

Taylor, J. A. 2004. The effect of iron in Al-Si casting alloys. $35^{\text {th }}$ Australian Foundry Institute National Conference, Adelaide, South Australia, 148-157.

Taylor, J. A. 2012. Iron-containing intermetallic phases in Al-Si based casting alloys. Procedia Materials Science, 1, 19-33. https://doi.org/10.1016/j.mspro.2012.06.004

Tillová, E., Chalupová, M. 2009. Structural analysis of Al-Si alloys, first ed., EDIS, Žilina, Slovakia.

Tillová, E., Chalupová, M., Hurtalová, L. 2011a. Evolution of phases in a recycled AlSi cast alloy during solution treatment. Chapter 21: The scaning Electron Microscopy. Dr. Viacheslav Kazmiruk, pp. 411 - 438, INTECH. DOI: 10.5772/34542

Tillová, E., Chalupová, M., Hurtalová, L., Duriníková, E. 2011b. Quality control of microstructure in recycled Al-Si cast alloys. Manufacturing Technology, 11, 70-76.

Tillová, E., Chalupová, M. 2014. Unconventional Metallographic Methods for the Structural Characterization of Laser Hardened Al-Zn-Si Cast Alloy. Materials Science Forum. 782, 369-372. https://doi.org/10.4028/www.scientific.net/MSF.782.369

VDS. 2000. Aluminium Recycling in Europe - the Road to High Quality Products. Aluminium Verlag, Düsseldorf, Germany. https://www.european-aluminium.eu/

Závodská, D., Tillová, E., Guagliano, M., Kuchariková, L., Chalupová, M. 2017. Fatigue resistance of self-hardening aluminium cast alloy. Mater. Today: Proceedings. 4, 6001-6006. https://doi.org/10.1016/j.prostr.2018.12.317

Wang, B. 2014. Alcoa Unveils Next-Generation Aluminum Materials Through Breakthrough Manufacturing Technology. Alcoa, Drucker Worldwide. 